\title{
MOLECULAR DETECTION AND CHARACTERIZATION OF STAPHYLOCOCCUS AUREUS ISOLATED FROM RAW MILK SOLD IN DIFFERENT MARKETS OF BANGLADESH
}

\author{
M. A. Islam, S. M. L. Kabir* and M. T. Rahman
}

Department of Microbiology and Hygiene, Bangladesh Agricultural University, Mymensingh-2202, Bangladesh

\begin{abstract}
The study was intended for molecular detection of $S$. aureus isolated from raw cow's milk. A total of 20 milk samples were collected from different upazila markets of Jamalpur, Tangail, Kishoreganj and Netrokona districts of Bangladesh. Milk samples were cultured onto various culture media for the isolation of bacteria. The isolated bacteria were identified by studying cultural properties on different selective media, biochemical tests, and finally by PCR. Out of 20 samples, 15 (75\%) milk samples were found to be positive for $S$. aureus. $S$. aureus specific $16 S \mathrm{rRNA}$ gene was amplified from all isolates and identified as $S$. aureus. Antimicrobial sensitivity test was carried out to ascertain the susceptibility of the organism to various antibiotics. Its results showed that the S. aureus isolates were resistant to amoxicillin (100\%), erythromycin (73.33\%) and tetracycline $(73.33 \%)$ but sensitive to azithromycin (93.33\%), ciprofloxacin (93.33\%), gentamicin (100\%), norfloxacin $(86.67 \%)$ and streptomycin $(86.67 \%)$.
\end{abstract}

Key words: Staphylococcus aureus, $16 \mathrm{~s}$ rRNA gene, raw milk

\section{INTRODUCTION}

Milk is considered as one of the high nutritional quality foods. Whole milk is the milk as it comes from the cow and contains about $3.5 \%$ milk fat. Research continues to expand the positive role of milk and milk products on individual's health. Evidence goes well beyond bone health to include its effects on immunity, mild hypertension, reducing selected cancers (Giovannucci et al., 1998), supporting weight management strategies and increasing satiety in dieters, among other positive effects. However, it is an excellent medium for growth and transmission of different bacterial pathogens to humans (Donkor et al., 2007). Staphylococcus aureus is an important food born pathogen and causes a mild skin infection to more severe diseases such as pneumonia and septicemia (Lowy et al., 1998). In Europe, milk and other dairy products are found responsible for 5\% of the staphylococcal outbreaks (Bianchi et al., 2014). Bacterial contamination of milk usually occurs during the milking process and this depends on the sanitary condition of the environment, utensils used for milking and the milking personnel. It could also result from micro-organisms that enter the udder through the teat opening canal (Smith et al., 2007). Staphylococcal food poisoning is often associated with the ingestion of manually handled foods that contain one or more highly heat stable staphylococcal enterotoxins. The safety of milk with respect to FBD is of great concern around the world. This is especially true in developing countries like where production of milk often takes place under unsanitary conditions and the consumption of raw milk which is typically produced in small dairy farms under unsatisfactory hygienic conditions is a common practice (Lee et al., 2003).Determination of levels of $S$. aureus and an evaluation of the antibiotic-resistant phenotypes of the isolates could serve as a tool for determining the hygiene standards implemented during milking. Data on antibiotic resistance could also be used to characterize this opportunistic pathogen, which may further limits the risks associated with the consumption of contaminated milk and its products (Wubete, 2004).

Several works have been done throughout the world regarding the milk and microorganisms of contaminated milk (Hassan et al., 2014). In Bangladesh, a few works have been done on isolation and molecular characterization of $S$. aureus from raw milk of cattle and buffalo (Islam et al., 2008; Hossain et al., 2011; Hossain, 2015). Moreover very few works have been reported in Bangladesh on molecular detection of S. aureus with other pathogenic organisms in cow's raw milk in a specific time period. So, keeping the above facts in mind, the present study was designed with an objective to molecular detection and characterization of bacteria isolated from raw milk samples. We studied the antimicrobial susceptibility patterns of isolated bacteria with the detection of $S$. aureus using $16 \mathrm{~s}$ rRNA gene.

*Corresponding e-mail address: 1kabir79@yahoo.com 


\section{MATERIALS AND METHODS}

\section{Sample collection}

A total of 20 cow's raw milk samples were collected from different upazila markets of Jamalpur, Tangail, Kishoreganj and Netrokona districts of Bangladesh using falcon tube. The samples were collected from July 2015 to December 2015 and investigation was carried out following collection. The collected milk samples were immediately transported on ice to the Microbiology Laboratory at the Department of Microbiology and Hygiene of BAU and District Veterinary Hospital, Sirajgonj for bacteriological analysis.

\section{Isolation and identification of $\boldsymbol{S}$. aureus}

The collected milk samples were performed 10 fold dilution using $0.1 \%$ peptone water and diluted samples were streaked onto $5 \%$ cattle blood agar (HiMedia ${ }^{\circledR}$, India) incubated at $37^{\circ} \mathrm{C}$ for overnight. Then the presumptive colonies of $S$. aureus were cultured onto mannitol salt agar (MSA) and then sub-cultured to get pure culture. These isolates were preserved for further bacterial identification. The isolates were identified as $S$. aureus on the basis of Gram staining, colony morphology on mannitol salt agar (MSA) (HiMedia®, India), betahemolytic patterns on blood agar, biochemical characterization of the isolates (using sugar fermentation test, indole and MR-VP test), catalase and coagulase tests. The pure colony of $S$. aureus were placed on the clean glass slide using sterile inoculation loop and a drop of respective reagents were added and mixed with the loop, then agglutination tests were performed. For catalase and coagulase tests $3 \%$ hydrogen peroxide and fresh rabbit plasma were used respectively. Further the isolates were confirmed by amplification of S. aureus specific $16 \mathrm{~S}$ rRNA gene.

\section{Bacterial Genomic DNA extraction}

The DNA template was prepared by boiling method. In brief for the preparation of DNA template, a single colony of bacteriological culture of $S$. aureus was taken in $250 \mu \mathrm{l}$ of DW in eppendorf tube, mixed well and then boiled for 10 minutes. After boiling the tubes were immediately placed on ice for cold shock followed by centrifugation at $10,000 \mathrm{rpm}$ for 10 minutes at $4^{\circ} \mathrm{C}$. The supernatant was collected which was further used as DNA template (Engler and Kelley, 2000).

\section{Identification of $S$. aureus by PCR}

PCR reaction was performed to detect $S$. aureus specific $16 S$ rRNA gene from isolated $S$. aureus in a thermal cycler (Astec, Japan). Two different primers pairs were used for this purpose, $16 S$ rRNA gene (F 5'CGATTCCUTAGTAGCGGCG-3' and R 5'-CCAATCGCACGCTTCGCC-3') according to the methods described by Swaminathan and Feng (1994). Each $20 \mu \mathrm{l}$ reaction mixture consists of $3 \mu 1$ genomic DNA, $10 \mu \mathrm{l}$ PCR master mixtures (Promega, USA), and $1 \mu \mathrm{l}$ of each of the two primers with the final volume adjusted to 20 $\mu \mathrm{l}$ with $5 \mu \mathrm{l}$ of nuclease free water. Amplification was done by initial denaturation at $95^{\circ} \mathrm{C}$ for 5 minutes, followed by denaturation at $94^{\circ} \mathrm{C}$ for 1 minute, annealing temperature of primers was $53^{\circ} \mathrm{C}$ for 1 minute and extension at $72^{\circ} \mathrm{C}$ for 1 minutes. The final extension was conducted at $72^{\circ} \mathrm{C}$ for 7 minutes. The total reaction was performed at 35 cycles. The amplified PCR products were resolved by electrophoresis in $2 \%$ agarose gel at 100v for 30 minutes, stained with ethidium bromide and finally visualized under UV trans-illuminator.

\section{Antibiotic Sensitivity Test}

All isolates of Staphylococcus aureus were tested for antimicrobial drug susceptibility against antimicrobial agents by disc diffusion method according to the guidelines of Clinical and Laboratory Standard Institute (CLSI, 2007). Sensitivity pattern of the isolates were determined against ciprofloxacin, azithromycin, gentamicin, amoxycillin, streptomycin, erythromycin, tetracycline and norfloxacin. Antimicrobial testing results were recorded as sensitive, intermediate sensitive and resistant according to zone diameter interpretative standards provided by CLSI, 2007. 


\section{RESULTS AND DISCUSSION}

20 raw milk samples were analyzed in the laboratory by different cultural, biochemical, staining and molecular methods to detect Staphylococcus aureus in raw milk. Out of 20 samples 75\% ( $\mathrm{n}=15)$ were contaminated with $S$. aureus. In blood agar the $S$. aureus produced $\beta$-hemolysis which is the typical characteristics of $S$. aureus (Figure 1).The growth of S. aureus on mannitol salt (MS) agar was confirmed by the fermentation of mannitol with change of color of media and formation of yellow color colonies (Figure 2). In Grams staining, the organism revealed Gram positive, violet colored, cocci shaped and arranged in grapes like cluster under light microscope (Figure 3). These isolates were positive for catalase and coagulase test. In catalase test, Hydrogen peroxide was broken-down into water and oxygen. Production of oxygen was indicated by bubble formation, whereas the negative control did not produce any bubble (Figure 4). The isolates were identified as $S$. aureus by coagulase test (Figure 5). The positive result of coagulase test was confirmed by the formation of curd like clotting compared to negative control. The optimized PCR assay was able to successfully amplify the target $16 S$ rRNA gene (1267 bp fragment) from the DNA templates of all isolated $S$. aureus. Result of PCR for $S$. aureus is shown in Figure 6. The organism was subjected to antimicrobial susceptibility test by disc diffusion method against 8 most commonly used antimicrobial agents. All isolates were found to be $100 \%$ resistant to amoxycillin, $11(73.33 \%)$ were resistant to erythromycin and $8(53.33 \%)$ were resistant to tetracycline. Furthermore, all isolates were susceptible to gentamicin, 14 (93.33\%) were susceptible to azithromycin, 14 (93.33\%) were susceptible to ciprofloxacin and $13(86.67 \%)$ were susceptible to norfloxacin (Figure 7).

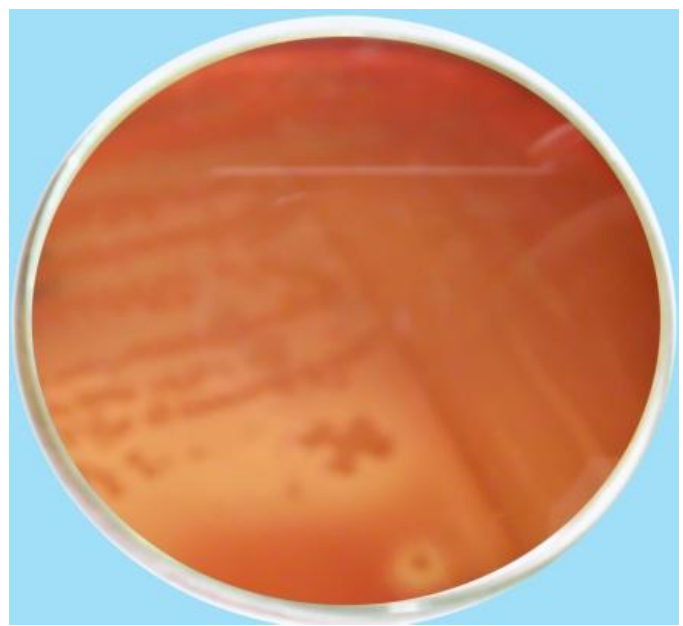

Figure 1. $\beta$-hemolysis on $5 \%$ cattle blood agar by $S$. aureus

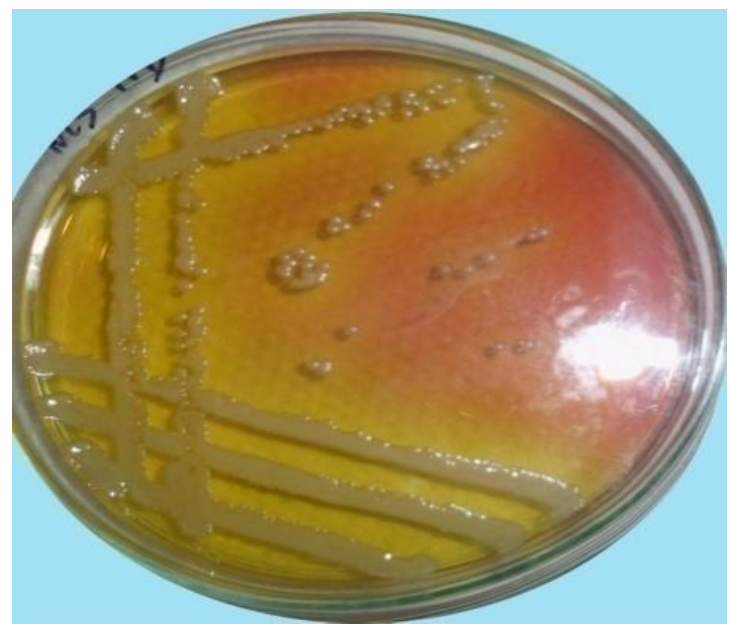

Figure 2. Growth of yellowish color colonies on MS agar by $S$. aureus 


\section{A. Islam and others}

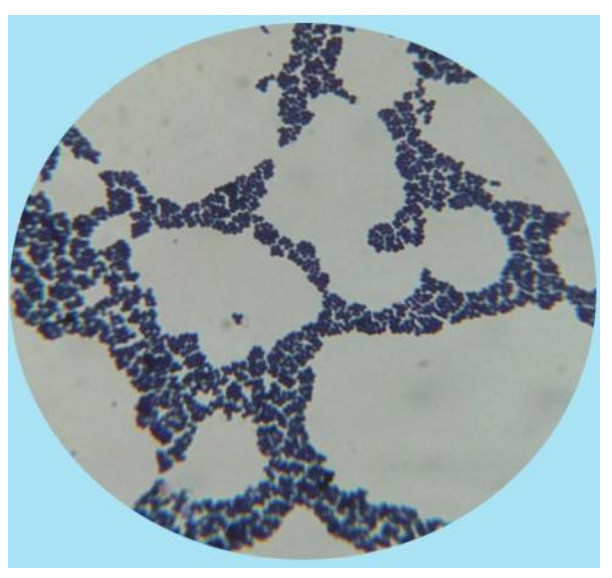

Figure 3. Gram positive, cocci, arranged in grapes like cluster of $S$. aureus under light microscope.

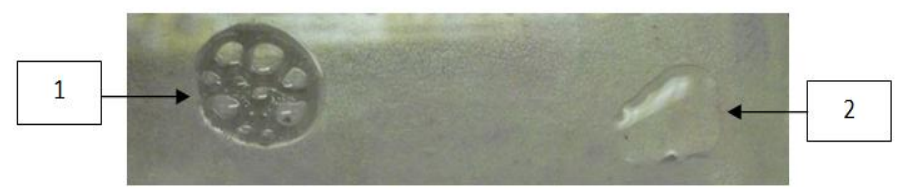

Figure 4. Catalase test of $S$. aureus.

1: Catalase positive;

2: Catalase negative

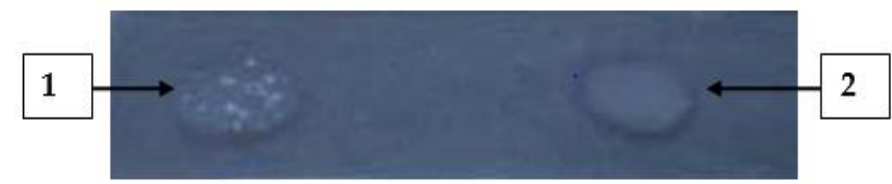

Figure 5. Coagulase test of $S$. aureus.

1: Coagulation of plasma by $S$. aureus;

2: Control

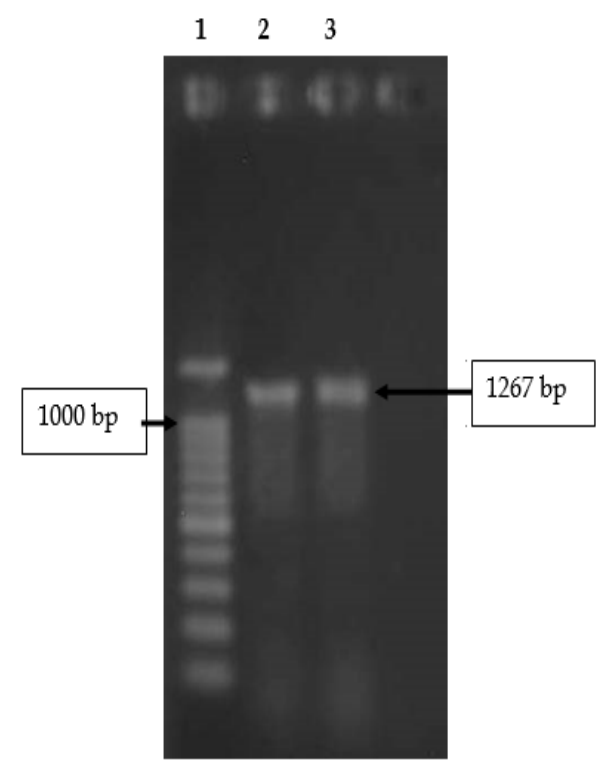

Figure 6. $16 S$ rRNA gene based PCR of S. aureus. Lane 1: 100 bp DNA ladder, Lane 2, 3: Tested samples were positive for $16 S$ rRNA gene. 


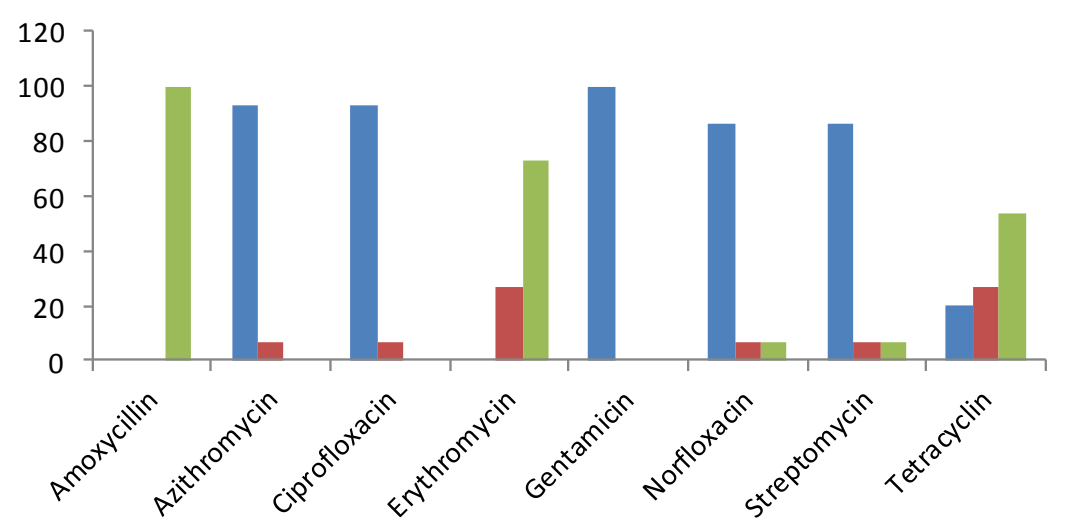

Figure 7. Antibiotic resistance patterns of S. aureus against commonly used antibiotics in Bangladesh

The above study revealed that cow's raw milk contained Staphylococcus aureus which can be transmitted to human through milking and consumption of milk. Milk is the best media for the growth of many pathogenic and non pathogenic bacteria. The $S$. aureus might be hazardous if proper boiling of milk is not done during consumption. It causes disease if proper hygienic procedure is not maintained during milking. In Bangladesh, Parveen (2000) characterized Staphylococcus aureus isolated from human and animal samples and Das (2012) isolate and identify Staphylococcus aureus from laboratory animals and human and also determine antibiogram profile. Jorgensen et al. (2005) stated that the presence of strains assigned to this Staphylococcus spp. in bulk milk or in raw milk products could reflect human contamination. In most cases, milk containing S. aureus were obtained from animals with subclinical mastitis. Zafolon et al. (2008) studied at Nova Odesa, São Paulo and showed that the prevalence of S. aureus was $54.4 \%$. The results obtained in our study are likewise higher when compared to those formerly documented (Shitandi and Sternesjo, 2004; Gundogan et al., 2006; Aziz et al., 2013; Hossain, 2015). Based on observations made throughout the collection of samples, we concluded that the improper hygiene practice and poor management before and during milking may have contributed to the contamination of milk with $S$. aureus, and the communal farms are more vulnerable in this case. The $S$. aureus incidence at a considerable high percentage indicates the alarming situation both for dairy farming and for public health. The presence of $S$. aureus in the milk sample is an appealing as well as an important finding of this study. S. aureus was resistant to multiple antibiotics which can cause serious health problems (Tenover, 2006; Hossain, 2015). Findings of antimicrobial susceptibility test were slightly correlated to De Oliveira et al. (2000), Guerin et al. (2003) where they analyzed 119 isolates of S. aureus collected between 1998 and 2000 in France from cows with clinical mastitis. Also, these findings were correlated to Hossain (2015), where 60 samples were investigated.

\section{CONCLUSION}

The present research was undertaken with a view to isolating and characterizing Staphylococcus aureus present in cow's raw milk. Out of 20 samples, $15(75 \%)$ milk samples were found positive for S. aureus. The isolates were identified as $S$. aureus on the basis of Gram staining, colony morphology, biochemical characterization, catalase and coagulase tests, slide agglutination test and PCR. Further the isolates were confirmed by amplification of $S$. aureus specific $16 S$ rRNA gene. Resistant pattern against broad spectrum antibiotic (e.g., amoxycillin) delimitate an alarming situation which needs special consideration.

\section{ACKNOWLEDGEMENTS}

We would like to thank sincerely the Food and Agriculture Organization of the United Nations (FAO) for giving financial and logistic support. 


\section{REFERENCES}

1. Aziz A, Akter MR, Rahaman MS, Khan MAS, Haque AKMZ, Jahan MS and Kabi SML (2013). Isolation, identification and antibiogram profiles of Staphylococcus aureus from commercial broiler flocks in Dinajpur District of Bangladesh with special focus on the determination of lethal effect of extracted toxin. Scientific Journal of Microbiology 2.

2. Bianchi DM, Gallina S, Bellio A, Chiesa F, Civera T and Decastelli L (2014). Enterotoxin gene profiles of Staphylococcus aureus isolated from milk and dairy products in Italy. Letters in Applied Microbiology 58: 190196.

3. CLSI (2007). Performance standards for antimicrobial susceptibility testing; seventeenth informational supplement. Clinical and Laboratory Standards Institute M100-S17: 1. Wayne, Pennsyslvania. pp. 32-50.

4. Das S (2012). Isolation and identification of Staphylococcus aureus from laboratory animals and human and also determine antibiogram profile. MS Thesis, submitted in the Department of Microbiology and Hygiene, Bangladesh Agricultural University, Mymensingh.

5. De Oliveira AP, Watts JL, Salmon SA and Aarestrup FM (2000). Antimicrobial susceptibility of Staphylococcus aureus isolated from bovine mastitis in Europe and the United States. Journal of Dairy Science 83: 855-862.

6. Donkor ES, Aning KG and Quaye J (2007). Bacterial contaminations of informally marketed raw milk in Ghana. Ghana Medical Journal 41: 58-61.

7. Eckburg PB, Bik EM, Bernstein CN, Purdom E, Dethlefsen L, Sargent M, Gill SR, Nelson KE and Relman DA (2005). Diversity of the human intestinal microbial flora. Science 308: 1635-1638.

8. Engler MD and Kelley LC (2000). A rapid DNA isolation procedure for the identification of Campylobacter jejuni by the polyinerasechain reaction. Letters in Applied Microbiology 31: 421-426.

9. Giovannucci E, Rimm EB, Wolk A, Ascherio A, Stampfer MJ, Colditz GA and Willett WC (1998). Calcium and fructose intake in relation to risk of prostate cancer. Cancer Research 58: 442-447.

10. Guerin FV, Carret $\mathrm{G}$ and Houffstchmitt P (2003). In vitro activity of 10 antimicrobials agents against bacteria isolated from cows with clinical mastitis. Veterinary Record 152: 466-471.

11. Gündogan N, Citak S and Turan E (2006). Slime production, DNAse activity and antibiotic resistance of Staphylococcus aureus isolated from raw milk, pasteurized milk and ice cream samples. Food Control 17: 389392.

12. Hossain AM, Al-Arfaj AA, Zakri AM, El-Jakee JK, Al-Zogibi OG, Hemeg HA and Ibrahim IM (2015). Molecular characterization of Escherichia coli $\mathrm{O} 157: \mathrm{H} 7$ recovered from meat and meat products relevant to human health in Riyadh, Saudi Arabia Saudi Journal of Biological Sciences 22: 725-729.

13. Hossain MF (2015). Study on microbial assessment of milk collected from different markets of Mymensingh, Gazipur and Sherpur districts with particular emphasis on the molecular detection and antimicrobial resistance of the isolated bacteria. MS thesis, submitted to the department of Microbiology and Hygiene, Bangladesh Agricultural University, Mymensingh-2202.

14. Islam MA, Mondol AS, de Boer E, Beumer RR, Zwietering MH, Talukder KA and Heuvelink AE (2008). Prevalence and genetic characterization of shiga toxin-producing Escherichia coli isolates from slaughtered animals in Bangladesh. Applied and Environmental Microbiology 74: 5414-5421.

15. Jorgensen HJ, Mørk T, Caugant DA, Kearns A and Rørvik LM (2005). Genetic variation among Staphylococcus aureus strains from Norwegian bulk milk. Applied and Environmental Microbiology 71: 8352-8361.

16. Lee HJ, Hoyt PR, White DG, Brody T, Baron F and Guatier M (2003). Methicillin (Oxacillin)-resistant Staphylococcus aureus strains isolated from major food animals and their potential transmission to humans. Applied and Environmental Microbiology 69: 6489-6494.

17. Lowy FD, Zinkawa K, Omoe S, Aasbakk K and Macland A (1998). Staphylococcus aureus infection New England Journal of Medicine 339: 520-532.

18. Perveen K (2000). Characterization of Staphylococcus aureus isolated from human and animal samples. MS. Thesis, submitted in the Department of Microbiology and Hygiene, Bangladesh Agricultural University, Mymensingh.

19. Shitandi A and Sternesjo A (2004). Prevalence of multidrug Resistant Staphylococcus aureus in milk from largeand small-scale producers in Kenya. Journal of Dairy Science 87: 4145-4149.

20. Smith K, Peter K, Daniela H and Melchior S (2007). Food borne pathogenic microorganisms and natural toxins. Food drug Administration Center Food Safety Applied Nutrition 10: 119-150.

21. Swaminathan B and Feng P (1994). Rapid detection of food-borne pathogenic bacteria. Annual Review of Microbiology 48: 401-426.

22. Tenover FC (2006). Mechanisms of antimicrobial resistance in bacteria. The American Journal of Medicine 119: S3-S10.

23. Wubete Y (2004). Bacteriological quality of bovine milk in small hollder dairy farms in debreZeit, Ethiopa Veterinary Research 4: 34-37.

24. Zafolon LF, Langoni H, Benvenutto F, Castelani L and Broccolo CR (2008). Aspectosepidemiológicos da mastitecausadapor Staphylococcus aureus. Veterinária e Zootecnia 15: 56-65. 